\title{
DISTÚRBIOS NEUROLóGICOS E ELECTROLfTICOS EM NEFRóTICO APÓS DIURESE RAPIDA PROVOCADA PELO ACTH
}

\author{
Hedda Arminante de Oliveira Penna* \\ Maria Aparecida Salgado Cesar **
}

\author{
ANTRANIK MANISSADJIAN * \\ GUILHERME MatTaR **
}

Distúrbios psiquicos e neurológicos vêm sendo observados em pacientes submetidos a tratamento pelo ACTH e pela cortisona, desde o início do emprêgo terapêutico dêsses hormônios.

Em 1949, Boland e Headley ${ }^{1}$ verificaram que a cortisona é capaz de produzir alterações no electrencefalograma. Em 1950, Soffer e col.2 observaram 6 casos com distúrbios psíquicos e 4 com síndrome convulsiva entre 34 pacientes com lupus eritematoso tratados pelo ACTH e pela cortisona. Hoefer e Glaser ${ }^{3}$ publicaram, em 1950, resultados de investigaçāo sistematizada feita em 15 pacientes com doenças diversas, submetidos a tratamento com ACTH; em 13 casos observaram alterações electrencefalográficas e em 10 assinalaram distúrbios neuropsiquicos; puderam êstes autores observar correlação entre o aparecimento de perturbações mentais e a presença de anormalidade nos electrencefalogramas; entretanto, não encontraram relação entre alteraçōes do electrencefalograma e os níveis de electrólitos sangüíneos. Em 1951, Lowell e col.4 relataram o aparecimento de convulsōes em paciente com asma brônquica tratado pela cortisona; nesse caso ocorreram alterações transitórias do electrencefalograma, permanecendo normal a electrolitemia. Dorfman e col. ${ }^{5}$ observaram, em 1951, a instalação de estado de mal epiléptico em três crianças de um grupo de 40 tratadas pelo ACTH e um caso de convulsão isolada em criança durante o uso de cortisona; os três pacientes tratados com ACTH permaneceram com anormalidades electrencefalográficas, sendo que em um, além de apraxia e afasia, persistiu a síndrome convulsiva. Bonham ${ }^{6}$ relatou, em 1953, o caso de um paciente falecido após o uso de ACTH e cortisona, com alucinações, euforia, confusão mental e convulsões generalizadas, não tendo o exame anátomo-patológico do sistema nervoso trazido explicação para o advento dessa sintomatologia.

Entre nós, Julião, Asșis e Pereira Gomes 7 relataram, em 1953, o caso de criança de 8 anos, portadora de síndrome nefrótica, que apresentou durante o tratamento com ACTH, cefaléia intensa, elevação acentuada da

Trabalho da Clínica Pediátrica da Fac. Med. da Univ. de São Paulo (Prof. Pedro de Alcântara), apresentado ao Departamento de Pediatria da Associação Paulista de Medicina em 12 novembro 1958. * Assistente. ** Médico residente. 
pressão arterial, sindrome convulsiva e coma; êsse paciente apresentou, como seqüelas, agnosia visual com provável hemianopsia homônima lateral direita, atrofia temporal da papila esquerda e anormalidades persistentes do electrencefalograma.

Greenman e col, 8 observaram, em 1955, 3 casos de hiponatremia num grupo de 30 crianças nefróticas tratadas com ACTH e dieta pobre em sódio. Dêsses 3 casos, 2 apresentaram convulsões e hipertensão arterial; em um dos últimos, em que havia atrofia cerebral residual, foi observada, além da hiponatremia, hipocalemia, hipocloremia e alcalose. Em 1958, Scaglione ${ }^{9}$ relatou 2 casos relativos a crianças com sindrome nefrótica, nas quais se instalaram graves perturbações do sistema nervoso central, na fase de diurese rápida conseqüente a tratamento por esteróides supra-renais; um dos casos foi tratado com ACTH endovenoso e o paciente apresentou hipocalemia, hipocloremia, alcalose e coma, tendo permanecido com seqüelas representadas por síndrome convulsiva e retardo intelectual; a outra criança, tratada com prednisona, apresentou hipocalemia, hipocloremia, alcalose, convulsōes, coma e alterações electrencefalográficas, permanecendo com episódios ocasionais de tipo paranóide e anormalidades no electrencefalograma.

\section{OBSERVACAO}

A. K., com 10 anos de idade, sexo masculino, brasileiro, raça amarela, internado em 6-2-1958 (Reg. Geral 449.453) com o diagnóstico de sindrome nefrótica. Há dois anos o paciente apresentou edema palpebral, logo generalizado; há seis meses vem apresentando ascite. História familiar - $O$ paciente tem Irmão de olto anos portador de doença semelhante. Exame clinico - Criança em mau estado geral, acentuadamente pálida, apresentando edema generalizado, sinais físicos de derrame pleural esquerdo e sinais de ascite. Pêso $32 \mathrm{~kg}$. Pressão arterial $110-90 \mathrm{~mm} \mathrm{Hg}$.

Exames de laboratório - Colesterolemia $495 \mathrm{mg} / 100 \mathrm{ml}$ de sôro. Calcemia 3,7 $\mathrm{mEq} / \mathrm{l}$. Fósforo inorgánico no sôro $4,6 \mathrm{mg} / 100 \mathrm{ml}$. Uréia $11 \mathrm{mg} / 100 \mathrm{ml}$. Glicemía $106 \mathrm{mg} / 100 \mathrm{ml}$. Proteinemia total $3,1 \mathrm{~g} / 100 \mathrm{ml}$. Sôro-albuminas $1,7 \mathrm{~g} / \mathrm{ml}$. Sôroglobulinas $1,4 \mathrm{~g} / \mathrm{ml}$. Lipóides birrefringentes presentes na urina. Proteinúria $10 \mathrm{~g} / 1$. Sedimento urinário: 4 hemácias e 2 leucócitos por campo.

Tendo os exames de laboratório confirmado o diagnóstico clínico, fol o paciente, a partir de 19 março 1958, submetido a tratamento pelo ACTH, ao lado de dieta pobre em sódio e de cloreto de potássio, nas doses que se vêem no quadro 1 .

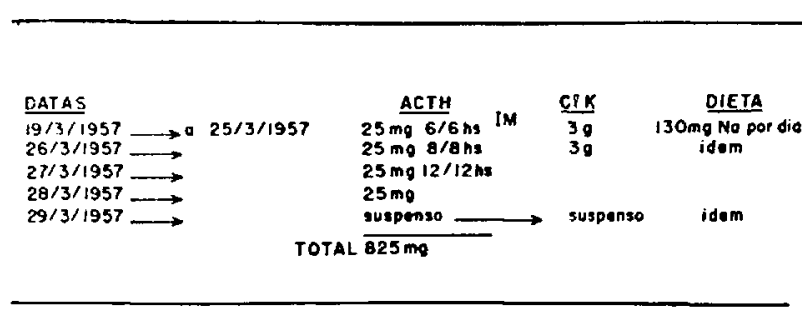

Quadro 1 - Caso A. K. Esquema do tratamento hormonai a que foi submetido o paciente. 
A dose total de ACTH recebida pelo paciente, por via intramuscular, foi de $825 \mathrm{mg}$.

No $4^{\circ}$ dia de tratamento, iniciou-se diurese abundante e, ao mesmo tempo, surgiu leve diarréia. No $8^{\circ}$ dia de tratamento foram observadas extrassistoles em salva, o que levou a redução das doses de hormônio, que foi suspenso no 110 dia. No 10 dja, manifestaram-se convulsōes tônico-clônicas, localizadas inicialmente no membro superior esquerdo, depois generalizadas; nessa ocasiāo, a pressão arterial do paciente era de $120-80 \mathrm{~mm} \mathrm{Hg;} \mathrm{no} \mathrm{periodo} \mathrm{pós-convulsivo} \mathrm{imediato} \mathrm{foram} \mathrm{observa-}$ dos nistagmo e desvio conjugado dos olhos e cabeça para a esquerda. Oito horas apos a primeira crise convulsiva, o paciente quelxava-se de tonturas, mostrava-se apático, respondia monossilabicamente a perguntas; a ausculta cardiaca revelava galope e a pressão arterial era de $110-90 \mathrm{~mm} \mathrm{Hg}$. Foi iniciada, então, a digitalizaçāo. Nesse dia foram feitos os seguintes exames subsidiários: Electrocardiograma, que sugeriu haver zona eletricamente inativável na parede livre do ventriculo esquerdo, com lesão subepicárdtca (fig. 1); Natremia $146 \mathrm{mEq} / 1$; Potassiemia 5,3 mEq/1; Cloremia $100 \mathrm{mEq} / \mathrm{l}$; Reserva alcalina $21 \mathrm{mEq} / 1$. Nesse dia, o exame dos fundos oculares resultow normal.

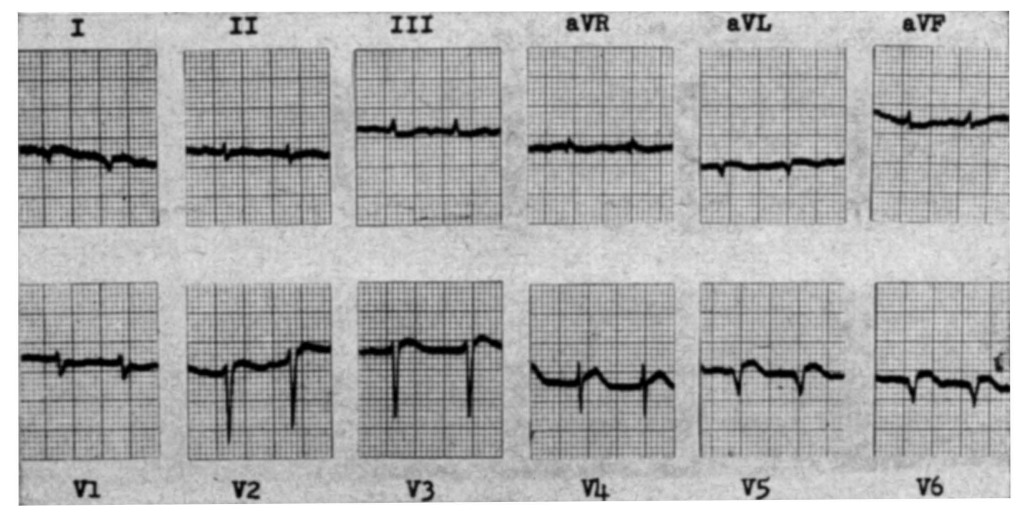

\begin{abstract}
Fig. 1 - Caso A. K. Primeiro electrocardiograma, obtialo em 28-3-58, no inicio da sintomatologia, mostrando sinais sugestivos de área de isquemia na parede livre do ventriculo esquerao.
\end{abstract}

No dia seguinte a crianca estava inconsciente, tendo apresentado várias convulsões localizadas na mão e comissura labial direita; continuava com ritmo de galope e ritmo respiratório irregular, com várias crises de apnéia; pressão arterial sistólica de $98 \mathrm{~mm} \mathrm{Hg}$, não tendo sido obtida a pressão diastóllca; diurese de $1.500 \mathrm{ml}$. Fol iniciada terapêtica com fenobarbital; a alimentaçáo fol suspensa, passando o paciente a receber suprimento calórico. por via parenteral.

No $13^{\circ}$ dia, novo electrocardlograma mostrou alteracão primária da repolarizaçāo ventricular (fig. 2); hematócrito $32 \%$; fundos oculares normais; exame do liquildo cefalorraquidiano inteiramente normal; diurese de $1.500 \mathrm{ml}$. Dosagens de electrólitos revelaram: Natremia 132,5 mEq/1; Potassiemia $3 \mathrm{mEq} / \mathrm{l}$; Cloremia 95 $\mathrm{mEq} / \mathrm{l}$; Reserva alcalina $26,6 \mathrm{mEq} / 1$. 


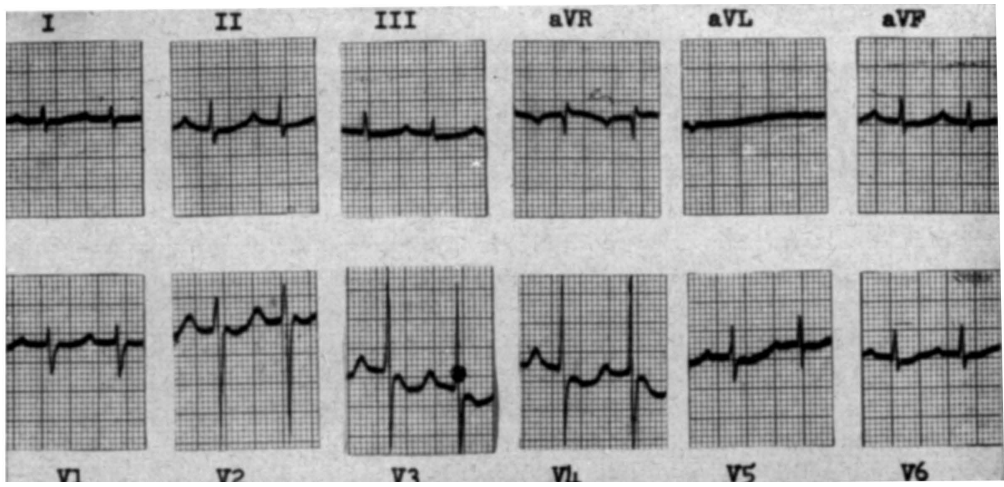

Fig. 2 - Caso A. K. Electrocardiograma feito em 31-3-58, mostrando sinais de alteração primária da repolarização ventricular.

No dia seguinte, estando o paciente ainda inconsciente, foi feito electrencefalograma, que revelou anormalidade continua, difusa, constituida por ondas $\delta$ de grande amplitude, com frequiência de 1,5 a 3 ciclos por segundo; havia moderada assimetría entre as áreas anteriores dos hemisférios, sendo a amplitude das ondas menor a direita; em conclusão, o electrencefalograma mostrou sinais de intenso sofrimento cerebral difuso (fig. 3). As dosagens de electrólitos nesse dia revelaram: Natremia $140 \mathrm{mEq} / \mathrm{l}$; Potassiomia 2,65 mEq/I; Cloremia $78 \mathrm{mEq} / 1$; Reserva alcalina $34 \mathrm{mEq} / \mathrm{l}$.

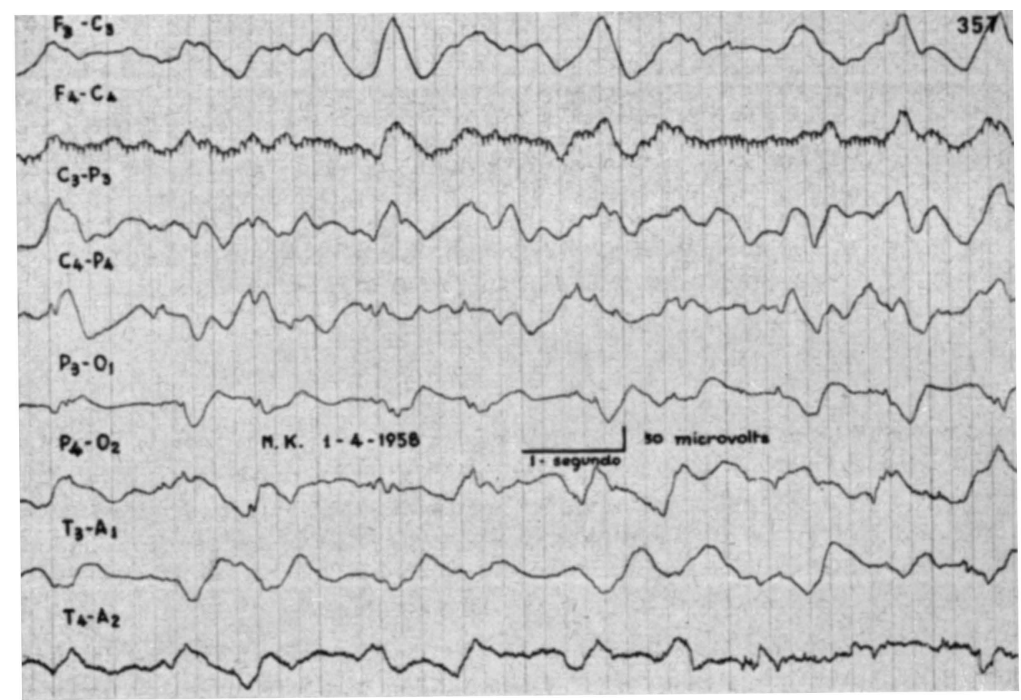

Fig. $3-$ Caso A. K. Electrencefalograma obtido durante o coma, mostrando intenso sofrimento cerebral direito difuso. 
No $15^{\circ}$ dia, a diurese foi de $900 \mathrm{ml}$ e os electrólitos estavam nos seguintes niveis: Natremia $128 \mathrm{mEq} / \mathrm{l}$; Potassiemia $3,3 \mathrm{mEq} / \mathrm{l} ;$ Reserva alcalina $26,6 \mathrm{mEq} / 1$. No $1^{\circ}$ dia a reserva alcalina era de $24,4 \mathrm{mEq} / 1$.

Os edemas foram gradualmente desaparecendo, mantendo-se a diurese em tôrno de $1.000 \mathrm{ml}$ diários; ao mesmo tempo, o paciente tornou-se gradativamente caquético, surgindo grandes escaras de decúbito.

No 219 dia foi reiniciada aljmentação, por sonda gástrica, passando a criança a receber dieta normocloretada, hiperprotéica e hipercalórica. O exame neurológico mostrou paciente inconsciente, não reagindo aos estímulos, permanecendo no decúbito em que era colocado; movimentos inconstantes de rotação da cabeca, de abertura e fechamento das pálpebras e de abdução e adução do membro inferior direito; reflexos tricipital e estilo-radial, esboçados; reflexos patelares e aqullianos ausentes; reflexo cutâneo-plantar em flexāo; hipotonia generalizada.

No 32 dia já o paciente estava semiconsciente, qbedecendo a ordens simples; assumia expressões mímicas grotescas, articulava palavras desconexas, chorava e ria imotivadamente; realizava, espontáneamente, movimentos de pequena amplitude com os membros superiores; só movimentava os membros inferiores quando estimulado; incontinência esfincteriana.

No $48^{\circ}$ dia o paciente estava consciente, obedecendo a ordens; não reconhecia letras; não reconhecia objetos e certas pessoas; não conseguia escrever; crises de alegria imotivada; mantinha os membros inferiores em semiflexão; realizava movimentos, porém não estendia totalmente os membros inferiores; movimentos da mão direita com amplitude diminuida; fôrca muscular diminuida à direita; reflexos profundos presentes e simétricos; reflexos superficiais normais.

Durante o periodo de desequilibrio electrolítico, o paciente recebeu parenteralmente água e os electrólitos adequados para tentar corrigílo. Três meses após, os exames de laboratório mostravam os seguintes resultados: Colesterol $268 \mathrm{mg} / 100 \mathrm{ml}$ de sôro; Proteinemia total $5,7 \mathrm{~g} / 100 \mathrm{ml}$; Sôro-albuminemia $3,7 \mathrm{~g} / 100 \mathrm{ml}$; Sôro-globulinemia $2,0 \mathrm{~g} / 100 \mathrm{ml}$; Proteinúria $9,0 \mathrm{~g} / 1$. Sedimento urinário: 30 hemácias, 5 leucócitos e 3 cilindros grosseiramente granulosos por campo.

Nessa ocasião foi iniciado tratamento no Serviço de Reabilitação da Clínica Neurológica do Hospital das Clinicas. Foi repetido o electrencefalograma 5 meses após o primeiro: assimetria entre os hemisférios, com anormalidade à esquerda (fig. 4). Pneumencefalografia, realizada por injeção de $60 \mathrm{~cm}^{3}$ de ar por via $10 \mathrm{~m}$ bar: sinais de atrofia cerebral difusa. Nessa mesma ocasiāo, foi realizada biopsia percutânea do rim direito que revelou quadro histológico de glomerulonefrite membranosa, havendo, porém, algumas lesões glomerulares sugestivas de processo em cronificação (hialinização). Exame neuro-ocular, feito a esta altura, revelou hemianopsia homônima latera] direita, tendendo à congruência, devida a lesão localizada à esquerda, provàvelmente no têrço anterior ou médio das radiações ópticas.

O paciente continuou a apresentar melhora gradual e progressiva, embora lenta, do quadro neurológico e do estado geral. Mantido sob a ação do fenobarbital nāo teve convulsões, que reapareciam a qualquer tentativa para diminuiçāo da dose do medicamento.

A diurese vinha se mantendo em tôrno de $1.000 \mathrm{ml}$ diários até 3 meses após o inicio do tratamento, porém, começou a diminuir nessa época. Foi, por êsse motivo, iniciada terapêutica com prednisona na dose de $\mathbf{1 5} \mathbf{m g}$ por dia e clortiazida, na dose de $500 \mathrm{mg}$ diários, enquanto que a dieta foi modificada no sentido de ser diminuida a administração de sódio. Ao lado dessa terapêutica foi reiniciada a administração de cloreto de potásslo por vía oral, na dose de 2 g diárias.

Oito meses após a internação, o exame neurológico mostrou: criança orientada auto e alopsiquicamente, com amnésia parcial; ocasionalmente mostra sinais de agressividade; não há distúrbio da palavra; agrafia e alexia; agnosia visual parcial; praxia parcialmente prejudjeada na mão direita; atitude indiferente; equilibrio 
normal; marcha cautelosa; motricidade voluntária diminuida apenas na mão direita; movimentação passiva normal; dismetria no membro superior direito, onde há decomposịão de movimentos; reflexos patelares, aquilianos e tricipitais, vivos e simétricos; sensibilidades tátil, barognóstica e estereognóstica comprometidas apenas na mão direita. Hipotonia muscular ainda evidente, porém muito mais acentuada do que nos exames anteriores.

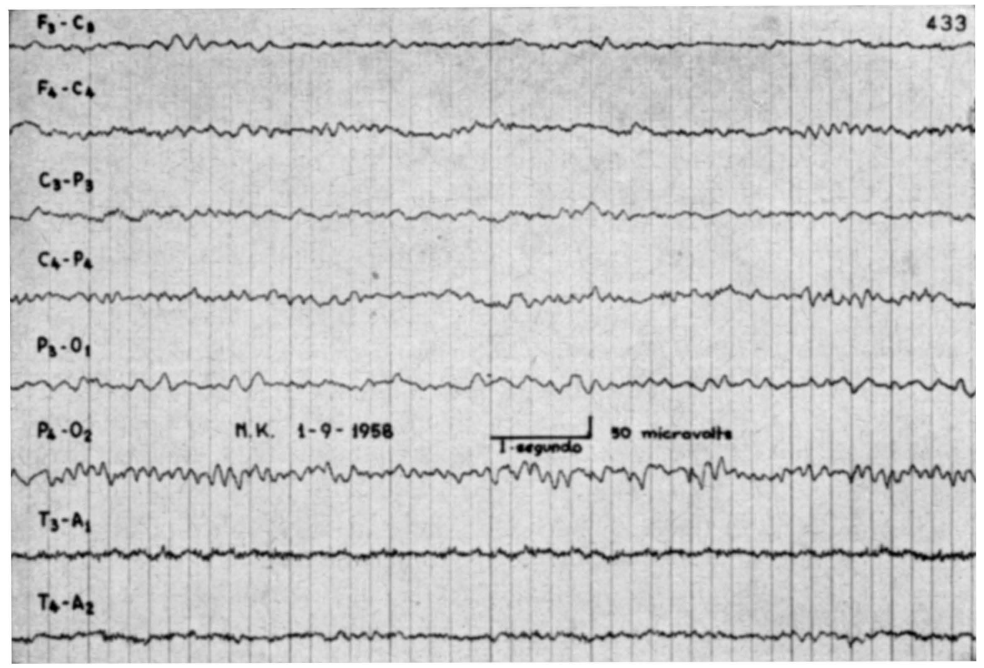

Fig. 4-Caso A. K. Segundo electrencefalograma, obtido 5 meses após o primeiro, mostrando assimetria entre os dois hemisférios e anormalidade $\grave{a}$ esquerda.

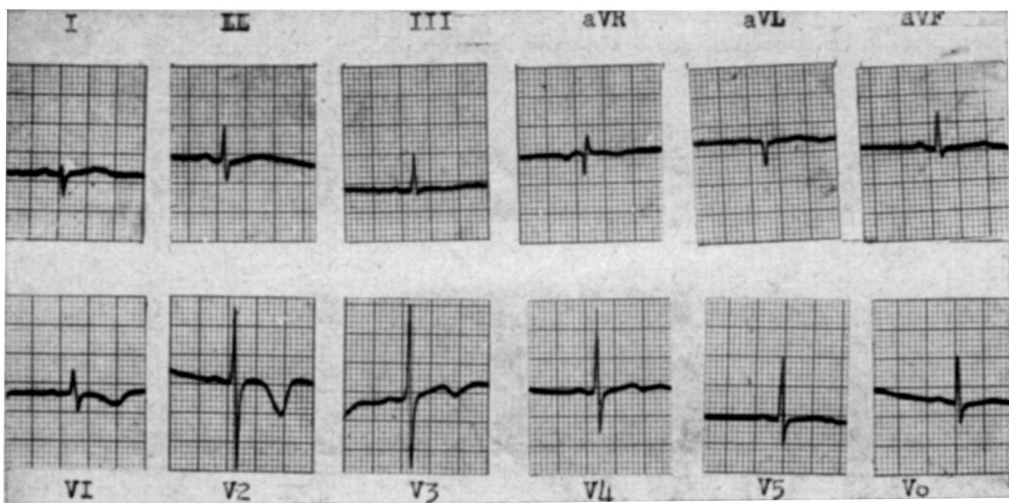

Fig. 5 - Caso A. K. Electrocardiograma feito em 24-10-58, ainda mostrando sinais de anormalidade de repolarizacão ventricular. 
Nessa ocasiăo foram feitos novos exames de laboratório - Exame de urina: densidade 1011; ausência de lipóides birrefringentes; proteínas 1,5 $\mathrm{g} / 1$; sedimento com 3 hemácias e 1 leucócito por campo. Proteinemia total $6,8 \mathrm{~g} / 100 \mathrm{ml}$ de sôro; Sóro-albuminemia $5,0 \mathrm{~g} / 100 \mathrm{ml}$; Sôro-globulinemia $1,8 \mathrm{~g} / 100 \mathrm{ml}$; Colesterolemia 272 $\mathrm{mg} / 100 \mathrm{ml}$; Natremia 143,6 mEq/l; Potassiemia 3,22 mEq/1; Cloremia $100 \mathrm{mEq} / \mathrm{l}$; Reserva alcalina $24,4 \mathrm{mEq} / \mathrm{I}$; Calcemia $5,6 \mathrm{mEq} / 1$. O electrocardiograma ainda mostrava sinais de anomalias de repolarização ventricular (fig. 5).

Nos quadros 2 e 3 podem-se observar, respectivamente, a evolução da sindrome nefrótica e as alterações electroliticas que ocorreram durante o tratamento.

\begin{tabular}{|c|c|c|c|c|}
\hline DATA & PESO & COLESIEROL. & PROTEINURIA & ALBUMINEMIA \\
\hline $10-3$ & $32 \mathrm{~kg}$ & $495 \mathrm{mo} / 100$ & $100 / 1$ & $1,7 p / 100$ \\
\hline $23-4$ & 17,600 & & & \\
\hline 20.5 & & 268 & 90 & 2 \\
\hline $\begin{array}{r}1-7 \\
8-10\end{array}$ & 17,800 & $\begin{array}{l}200 \\
272\end{array}$ & $\begin{array}{l}5 \\
1.5\end{array}$ & $\begin{array}{l}2,3 \\
5\end{array}$ \\
\hline
\end{tabular}

Quadro 2 - Caso A. K. Evolução da sindrome nefrótica em relação ao pêso, colesterolemia, proteinüria e albuminemia.

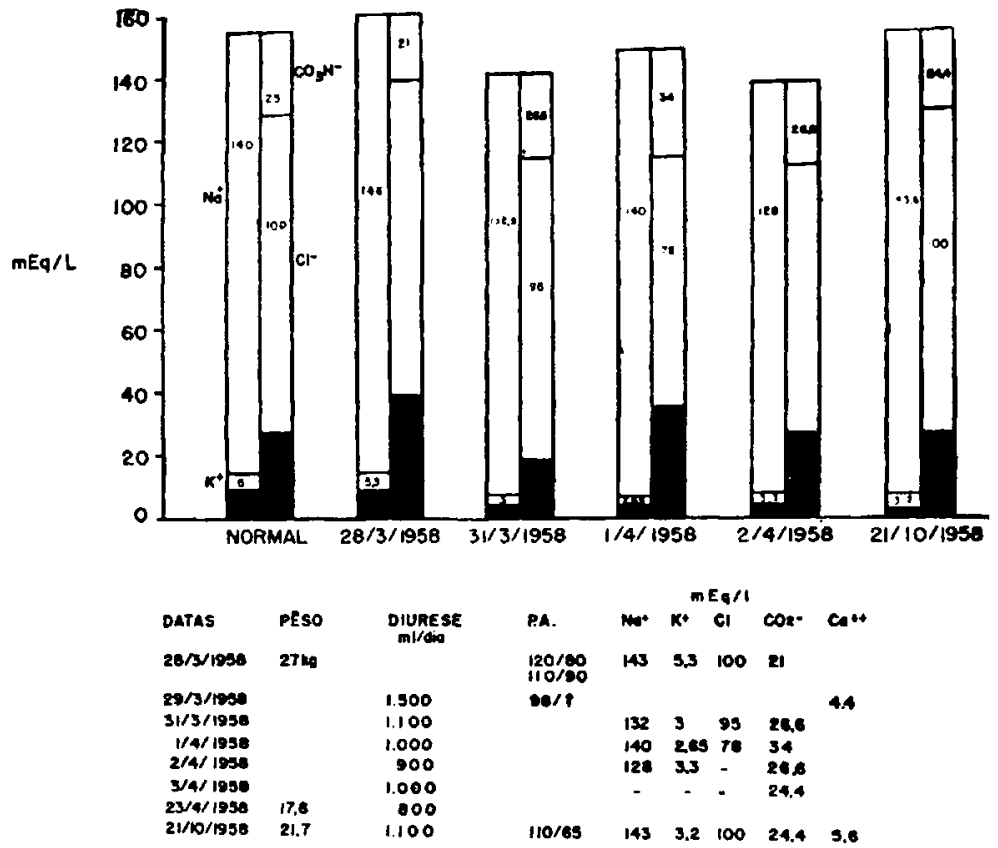

Quadro 3-Caso A. K. Ionogramas do paciente comparados com o de criança normal; na parte inferior do quadro estão relacionados pêso, diurese e pressão arterial com os niveis electroliticos. 


\section{COMENTARIOS}

Embora seja de indiscutivel valor, como ressaltam Greenman e col. ${ }^{8} \mathrm{e}$ Scaglione ${ }^{9}$, a terapêutica da síndrome nefrótica pelo $\mathrm{ACTH}$, cortisona e drogas de ação similar envolve riscos que podem assumir extrema gravidade. Os acidentes decorrentes dessa terapêutica muitas vêzes não regridem mesmo após a suspensão da medicação; no caso de Bonham ${ }^{6}$ ocorreu óbito 18 dias após a interrupçāo do tratamento.

Podem êsses hormônios provocar distúrbios psíquicos que vão desde simples euforia até graves manias; podem ocorrer, também, estado de mal epiléptico, alterações profundas do electrencefalograma e coma. Em certos casos as alterações neurológicas podem ser irreversiveis, restando graves seqüelas (atrofia cerebral, rebaixamento intelectual, perturbações da memória, alterações visuais). Entre as seqüelas apresentadas pelo nosso paciente destacam-se as alterações do electrencefalograma, a atrofia cerebral difusa, a síndrome convulsiva e a hemianopsia homônima lateral direita.

Em alguns casos há elevação da pressão arterial, acompanhada às vêzes de hipertensão intracraniana; em outros, porém, tanto a pressão arterial, como a intracraniana se mantêm normais. No caso presente ocorreram alteraçōes neurológicas graves, associadas a anormalidade profunda do electrencefalograma, embora permanecessem normais as pressões arterial e intracraniana.

Além dos distúrbios já mencionados, podem surgir, isolada ou concomitantemente, desequilibrios electrolíticos do sôro. Greenman e col. ${ }^{8}$ salientam que a hiponatremia constitui risco real, embora pouco freqüente, do tratamento hormonal da sindrome nefrótica; êsses autores mencionam a ocorrência de hiponatremia após paracenteses, crises de vômitos e surtos de diarréia. O nosso paciente apresentou, anteriormente às perturbaçōes neurológicas, diarréia de grau leve.

Em um dos pacientes de Greenman e col. ${ }^{8}$, nos 2 casos de Scaglione ${ }^{9}$ e no caso presente, além da hiponatremia, foram, tambẻm, assinaladas hipocalemia, hipocloremia e alcalose, em uma ou outra fase da evolução da síndrome. Note-se que no caso presente, como também em um dos casos de Scaglione ${ }^{9}$, os sintomas neurológicos precederam as alteraçōes electrolíticas do sôro.

Scaglione ${ }^{9}$, baseado no fato de que nos seus casos as alteraçōes surgiram na fase de diurese rápida provocada pelo tratamento hormonal, oferece, como tentativa de explicação para a instalação das mesmas, a perda de potássio pelas células. Essa queda de concentração de potássio intracelular seria secundária às grandes perdas obrigatórias pela urina, que levariam à expoliação do líqüido extracelular em potássio, com conseqüente passagem dêsse ion do interior das células para o líqüido extracelular, numa tentativa de recomposição dêste último; os ions sódio e hidrogênio entrariam para as células, como mecanismo compensatório. Nessa fase, o potássio poderá estar em limites normais no sôro, embora as células já estejam expoliadas. Re- 
sultaria dêsse mecanismo a existência concomitante de alcalose extracelular e acidose intracelular. Esta última, quando prolongada, determinaria perturbaçōes nas funções celulares. Estas perturbações resultariam, para o lado das células do túbulo renal, numa incapacidade de reabsorção do cloro; dai a hipocloremia.

Essas lesōes celulares, pela sua própria natureza, seriam generalizadas, o que, no caso presente, explicaria as profundas alterações electrocardiográficas (fig. 1) com sinais de isquemia miocárdica, na vigência de electrolitemia normal.

Concluindo, devemos ressaltar novamente que o emprêgo terapêutico dos corticóides supra-renais apresenta riscos e que a melhor precaução contra o aparecimento de sintomas adversos é o próprio conhecimento da possibilidade de sua ocorrência. Dosagens periódicas de electrólitos no sôro devem ser realizadas durante o uso dêsses hormônios.

Scaglione ${ }^{9}$ recomenda, como medida terapêutica, visando atenuar os efeitos dessas alterações electrolíticas, a administração de potássio endovenosamente ao menor indicio da instalação dessas perturbaçōes.

\section{RESUMO}

Os autores apresentam o caso de criança de 10 anos, portadora de síndrome nefrótica, que, durante a fase de diurese rápida conseqüente à administração de $\mathrm{ACTH}$, apresentou crises convulsivas, coma, alterações do electrencefalograma, do electrocardiograma, hiponatremia, hipocalemia, hipocloremia e alcalose. Como principais seqüelas, o paciente apresentava, ao ter alta hospitalar, síndrome convulsiva e hemianopsia homônima lateral direita. Os autores comentam o possivel mecanismo dessas alteraçóes.

\section{SUMMARY}

\section{Electrolyte and neurological disturbances in a nephrotic boy following rapid diuresis induced by $A C T H$ administration.}

Report of a case of a 10 year old nephrotic boy that developed convulsions progressing to a coma, severe electrocardiographic and electroencephalographic changes, hyponatremia, hypokalemia, hypochloremia and alkalosis following massive diuresis secondary to the administration of ACTH. The patient remained with a convulsive disorder and a right lateral homonymous hemianopsia. The mechanism of those severe disturbances is commented on.

\section{REFERENCIAS}

1. BOLAND, E. W.; HEADLEY, N. F. - Effects of cortisone acetate on rheumatoid arthritis. J.A.M.A., 141:301, 1949. 2. SOFFER, J.; LEVITT, M. F.; BAEHR, G. - Use of cortisone and adrenocorticotropic hormone in acute lupus erythematosus. 
Arch. Int. Med., 86:558, 1950. 3. HOEFER, P. F. A.; GLASER, G. H. - Effects of pituitary adrenocorticotropic hormone (ACTH) therapy. Electroencephalographic and neuropsychiatric changes in fifteen patients. J.A.M.A., 143:620, 1950. 4. LOWELL, F. C.; FRANKLIN, W.; BEALE, H. D.; SCHILLER, I. W. - Occurrence of convulsive sizures during treatment of asthma with cortisone acetate. New England J. Med., 244:49, 1951. 5. DORFMAN, A.; APTER, N. S.; SMULL, K.; BERGENSTAL, D. M.; RICHTER, R. B. - Status epilepticus coincident with use of pituitary adrenocorticotropic hormone: report of three cases. J.A.M.A., 146:25, 1951. 6. BONHAM, D. T. A report on the death of a patient with convulsive seizures during treatment of rheumatoid arthritis with cortisone, ACTH and post-partum plasma. New York State J. Med., 53:1114, 1953. 7. JULIAO, O. F.; ASSIS, L. M.; GOMES, J. P. - Complîcações neurológicas no decurso do tratamento pelo ACTH: a propósito de um caso de agnosia visual. Arq. Neuro-Psiquiat., 11:403, 1953. 8. GREENMAN, L.; WEIGAND, F. A.; DANOWSKI, T. S. - Therapy of the nephrotic syndrome. Am. J. Dis. Child., 39:169, 1955. 9. SCAGLIONE, P. R. - A complication in treatment of nephrosis. Pediatrics, 21:337, 1958.

Clinica Pediátrica - Hospital das Clinicas da Fac. Med. da Univ. de São Paulo - Caixa Postal 3461 - São Paulo, Brasit. 